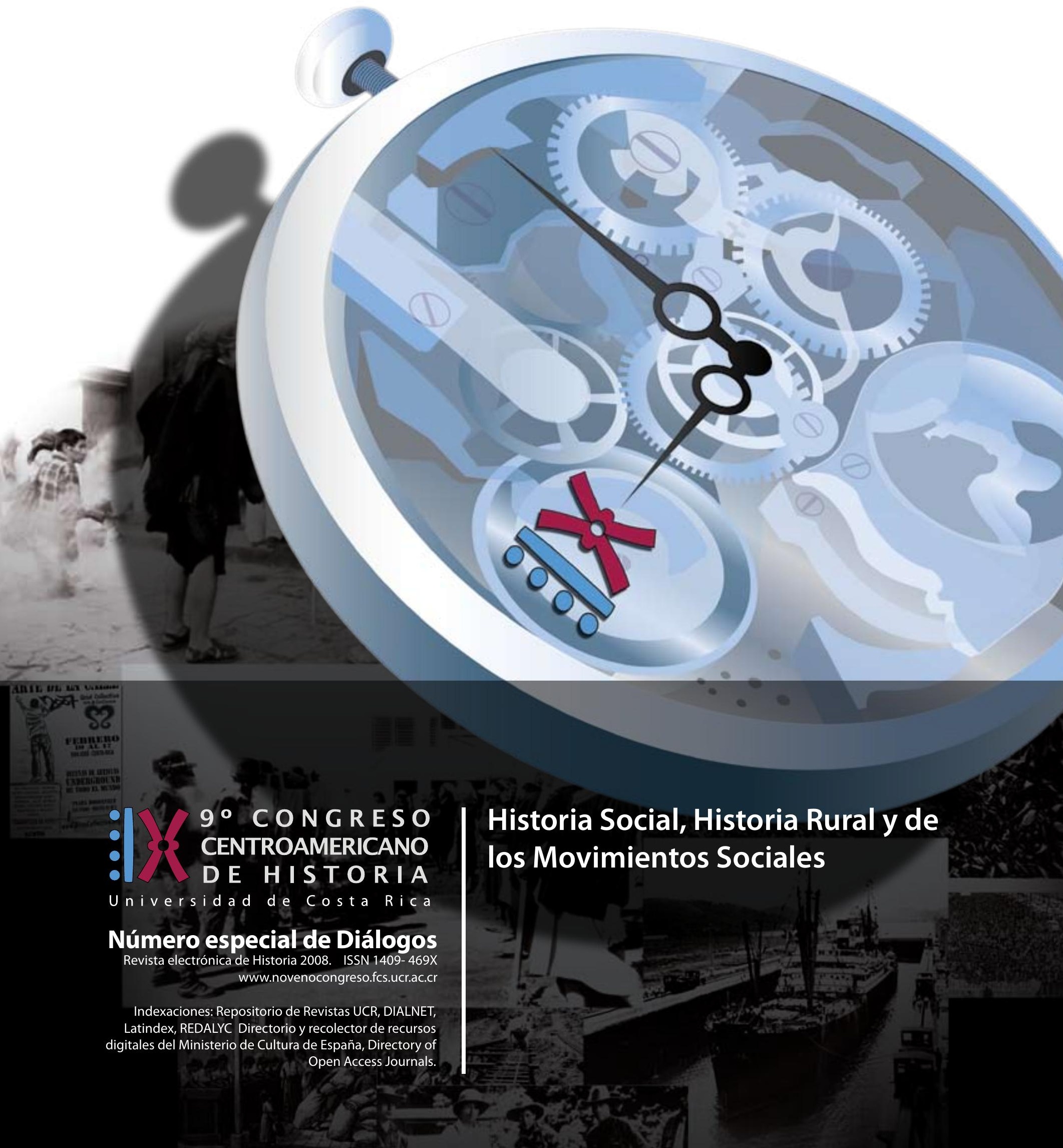




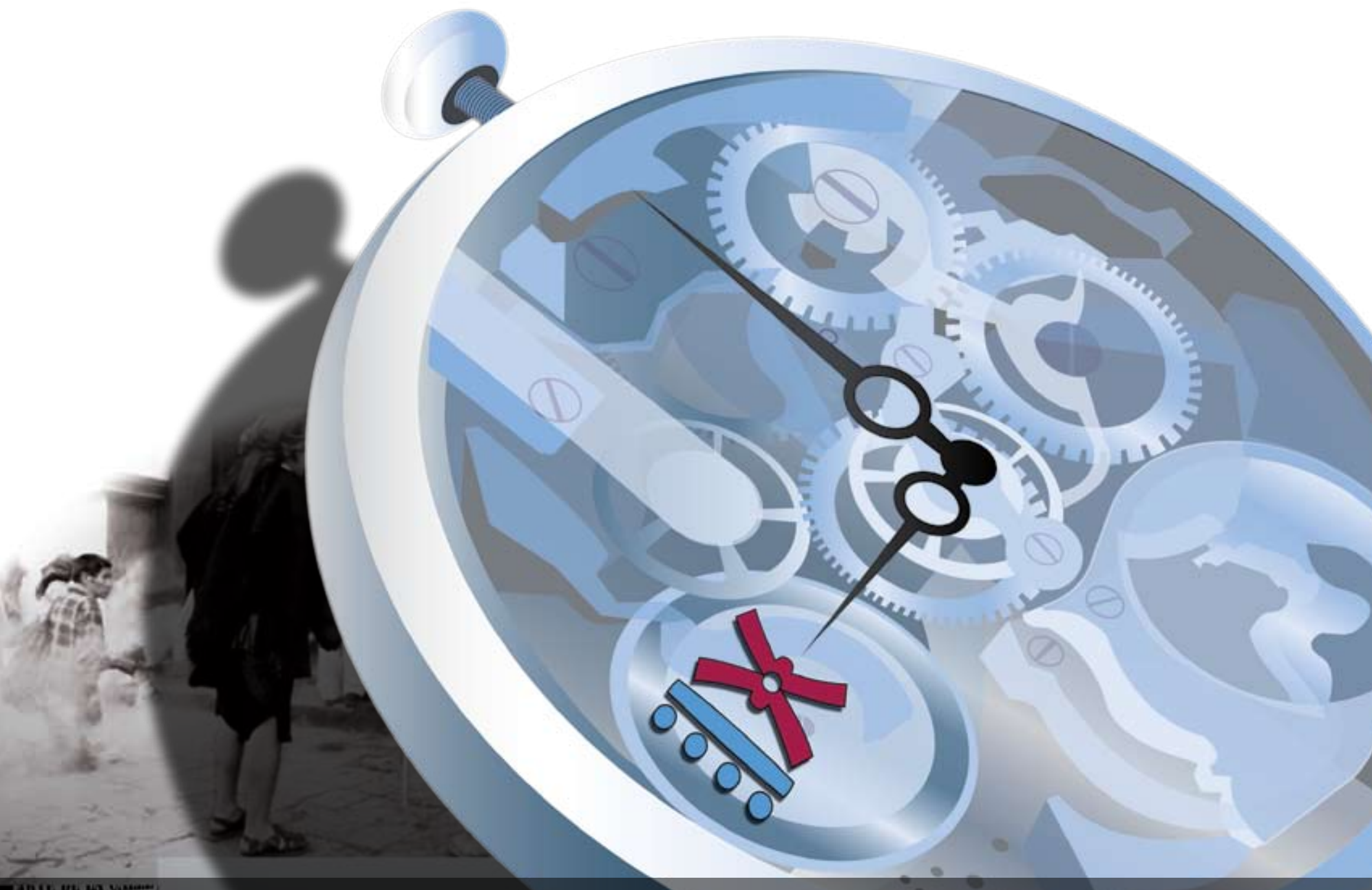

$9^{\circ}$ CONGRESO 2. CENTROAMERICANO DE H ISTO R I A

Universidad de Costa Rica ISSN 1409- 469X

Fecha de recepción: 15 de mayo 2008 Fecha de aceptación: 30 de mayo 2008

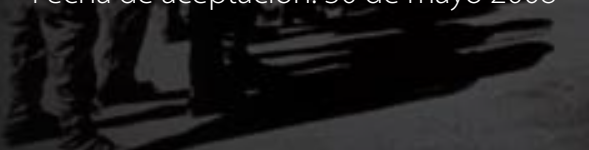

La consolidación de una empresa cooperativa frente a la actual crisis del mercado cafetero. El caso de CoopeLibertad R.L. (2000-2006).
Miembros del Consejo Editorial:

Dr. Ronny Viales, Dr. Juan José Marín

Editores Técnicos:

Allan Fonseca, Andrés Cruz, Gabriela Soto
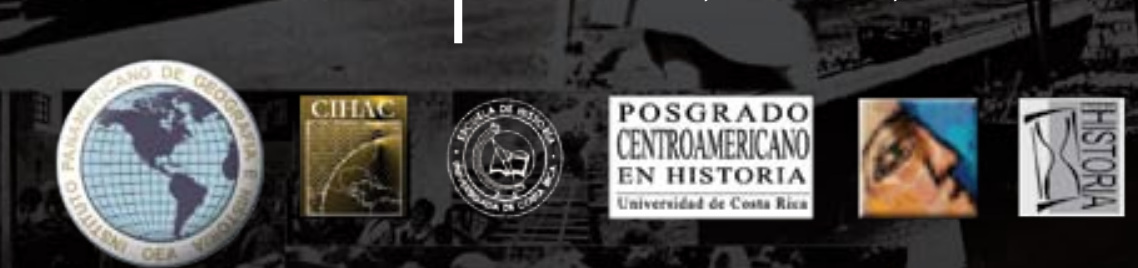
ON $9^{\circ}$ CONGRESO

:U CEE HISTORIA

Universidad de costa Rice

Indexaciones: Repositorio de Revistas UCR, DIALNET, Latindex, REDALYC Directorio y recolector de recursos digitales del Ministerio de Cultura de España, Directory of Open Access Journals. Diálogos Revista Electrónica de Historia ISSN 1409-469X. Número especial 2008. Dirección web: http://historia.fcs.ucr.ac.cr/dialogos.htm

\title{
La consolidación de una empresa cooperativa frente a la actual crisis del mercado cafetero. El caso de CoopeLibertad R.L. (2000-2006).
}

\author{
Allan Víquez \\ Universidad Nacional \\ Costa Rica
}




\section{Preámbulo}

El abandono de las cláusulas económicas contenidas en el Convenio Cafetero en 1989 condujo a una etapa severa para el sector en Costa Rica y en varios países productores de café. La estrategia de liberalización del mercado cafetalero propuesta por los países importadores del grano provocó una fuerte baja en las cotizaciones del grano, impactando de esta manera las distintas esferas que componen la cadena de comercialización. En este contexto, la crisis institucional surgida a raíz del ajuste estructural limitó la intervención estatal en los sectores tradicionales de la economía y restringió el apoyo al sector cooperativo cafetalero a lo largo de la década de 1990.

La presente investigación analiza las respuestas ofrecidas por un grupo cooperativo, Libertad R.L., ante los duros efectos producidos por las constantes fluctuaciones de precios internacionales del café durante el período 2000-2006, de cara a la alta competencia de empresas comercializadoras transnacionales que incursionaron en el sector. De igual manera, las páginas siguientes explican el peso específico de una exitosa estrategia centrada en el mejoramiento de la calidad y su relativa incidencia sobre la relación asociados-cooperativa.

Esta presentación abarca el lapso comprendido entre el año 2000 y el 2006, fase en la cual el sector cafetero afrontó una nueva baja en los precios del grano y en la cual la cooperativa replanteó su esquema estratégico, basado en el acopio y procesamiento de café de alta calidad, con el fin de mitigar y sobreponerse a los efectos de esta crisis y de solventar su situación económica. Al mismo tiempo, la aplicación de políticas encausadas a mejorar la calidad del café tuvieron cierto impacto sobre las relaciones asociado-cooperativo.

Cabe considerar las políticas y acciones de CoopeLibertad con el fin de subsanar su 
crisis financiera, agudizada tanto por las constantes fluctuaciones de precios como por el fuerte proceso de urbanización existente en la provincia de Heredia, así como por la consolidación de empresas transnacionales dentro de la cadena de comercialización del grano. Con posterioridad se considerará el impacto de estas transformaciones sobre la relación asociados-cooperativa. Antes de pasar a analizar estos aspectos de fondo, será necesario plantear la situación del entorno cooperativo nacional y las circunstancias en las cuales se desenvolvió CoopeLibertad R.L ante las recurrentes fluctuaciones en los precio del grano a partir de 1989, año clave para el sector cafetalero nacional.

\section{La crisis del sector cooperativo cafetalero y la situación de CoopeLibertad R.L.: el problema de investigación.}

Los Programas de Ajuste Estructural y su impacto inmediato sobre el papel del Estado en la economía, asestaron un fuerte golpe al conjunto de las cooperativas agrícolas, en especial aquellas dedicadas a la actividad cafetalera las cuales habían recibido apoyo estatal desde el ascenso de los socialdemócratas al poder a partir de la segunda mitad del siglo XX. Durante la década de 1980, los gobiernos de turno mostraron su preocupación por mantener excelentes relaciones financieras con los Estados Unidos a fin de solventar la deteriorada economía costarricense y, paralelamente, como una forma de manifestar su apoyo en la causa contra el sandinismo nicaragüense.

De esta manera, organismos financieros internacionales como la Agencia Interamericana 
de Desarrollo (AID) y el Fondo Monetario Internacional (FMI) concedieron préstamos destinados a crédito cooperativo con el fin de fomentar actividades agrícolas no tradicionales, y de esta manera incentivar el sector exportador. Gran parte del crédito otorgado al movimiento fue transferido por medio de las instancias gubernamentales, reduciendo las funciones de canalización de crédito del sistema bancario nacional y dando una vida artificial al movimiento; lo cual se evidenció con el retiro de la ayuda económica por parte de la Agencia a partir de la década de 1990.

El entorno institucional sufrió un debilitamiento en lo que respecta el apoyo a las empresas cooperativas de caficultores. Esto se hizo aún más evidente a inicios de la década, cuando los organismos financieros internacionales dejaron de financiar los proyectos de diversificación productiva que iniciaron en el decenio la década de 1980 a raíz de la crisis financiera, lo cual resultó contraproducente para muchas cooperativas que dependían de estos proyectos de financiamiento. A esto, se suma el hecho de que la Federación de Cooperativas de Caficultores (FEDECOOP R.L) perdió credibilidad y legitimidad como agente de cohesión del movimiento debido a la falta de autonomía e intervención de fuerzas políticas a su interior. ${ }^{1}$

Al iniciar la década de 1990, la cooperativa había sufrido las consecuencias de la baja en las cotizaciones del grano. Los recursos obtenidos por las ventas de café se redujeron de manera sustancial en el año cafetero 1991-1992, lo cual afectó significativamente los pagos por adelanto de cosecha, cuyos montos fueron insuficientes para cubrir los gastos de operación en el sector. Esto a su vez repercutió en los volúmenes de producción de café a procesar, lo que a la vez perturbó las ventas de café de la cooperativa en el mercado nacional. Del ingreso obtenido

1 Según el señor Oscar Luis Salazar, este organismo actuó más en defensa de la clase política que de las cooperativas que protegía: “... [cuando FEDECOOP] comenzó a politizarse, los partidos políticos influían en quien era el gerente, comenzó a politizarse (...) y como todo, cuando se entroniza una influencia política muy grande... y para mí fue una pérdida importante porque en este país no existe una institución que tenga el prestigio internacional y la fuerza que tenía Fedecoop en el momento que estaba bien.” 
por venta de café, CoopeLibertad adquiere un ingreso del 9 por ciento por ciento que destina para administración, manutención de instalaciones y otros servicios que brinda. La cantidad restante representa el precio de liquidación que recibe el productor, del cual se deducen impuestos como el de la renta y mantenimiento del ICAFE. ${ }^{2}$

Una de las más frecuentes respuestas del productor fue el abandonar la cooperativa, con el fin de recuperar parte de su patrimonio. Esto produjo que la cooperativa se descapitalizara de manera paulatina y que contrajera las deudas del asociado, al punto de comprometer y limitar la capacidad de crédito para el productor:

“el viernes había que pagar 150 millones de pesos en crédito, adelantos. Venía el productor, y no había un cinco! Entonces ahí corrió el gerente llamando al banco, llamando aquí, llamando allá, a otra cooperativa... era un hueco [financiero], porque la cooperativa no tenía recursos ni para su propio funcionamiento.” ${ }^{3}$

De esta manera, la primera prioridad de la cooperativa era buscar recursos financieros, no solo para solventar las necesidades del productor, sino las propias. Así se concertaron diversos préstamos con instituciones como FEDECOOP, INFOCOOP y entidades del sistema bancario nacional para hacer frente a esas necesidades, lo cual incrementó el nivel de endeudamiento de la cooperativa (Ver Gráfico No. 1).

2 Entrevista inédita con Gerardo Campos, empleado de la cooperativa. Barva de Heredia, 29 de agosto del 2007.

3 Entrevista inédita con Oscar Luis Salazar, empleado de la cooperativa. Barva de Heredia, 29 de agosto del 2007. 


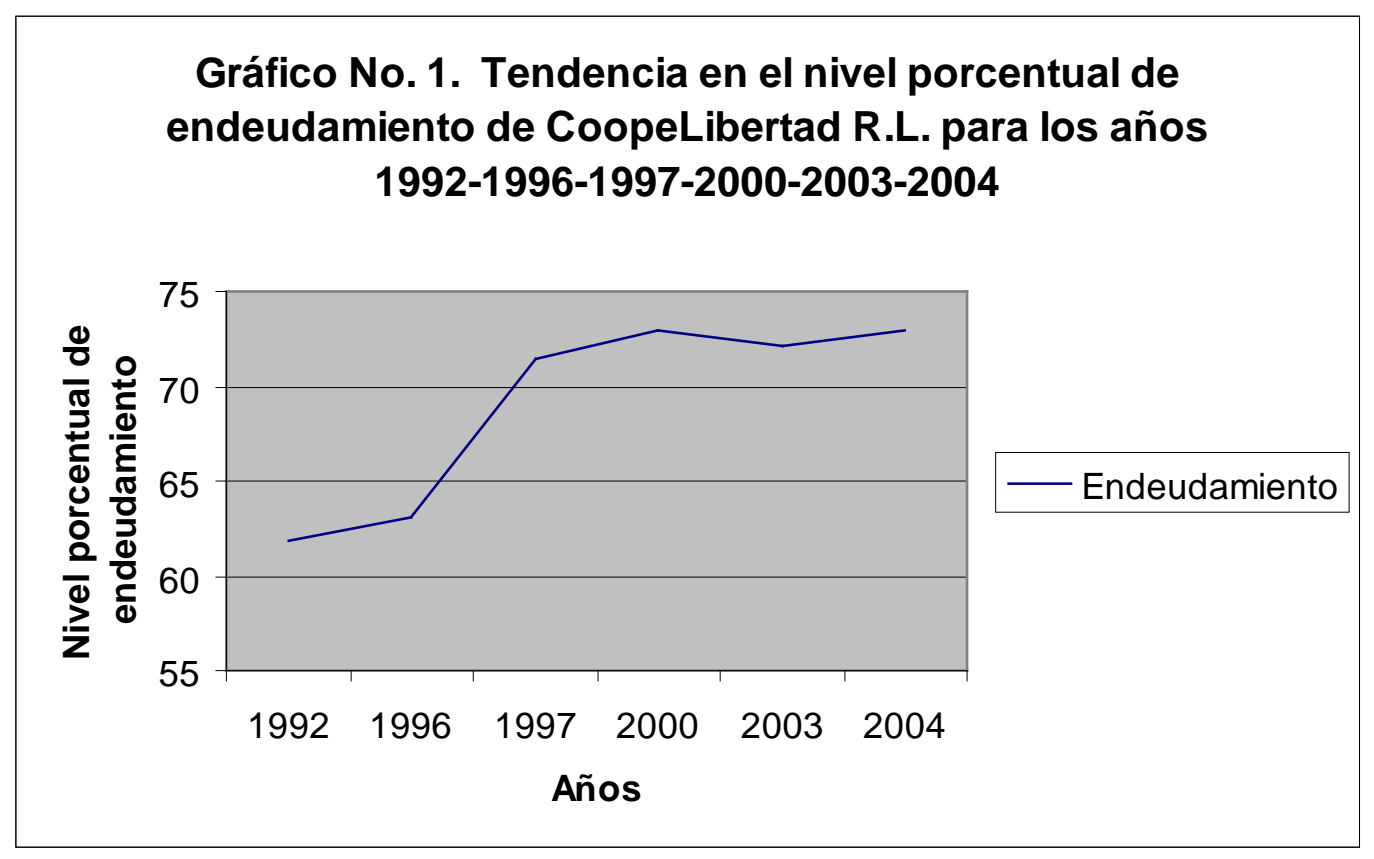

Fuente: Elaboración propia a partir de: CoopeLibertad R.L. Informes de Administración y Gerencia. Asamblea General de Delegados No 78, marzo del 2004 y No 79, abril de 2005.

2. Calidad versus volumen: La importancia del mejoramiento del grano de oro en el esquema estratégico de CoopeLibertad R.L

Al iniciar el año 2003, Carlos Murillo, por entonces gerente de CoopeLibertad R.L, hizo hincapié en el compromiso que debía adquirir el grupo para enfrentar la crisis del mercado cafetero:

“Libertad y sus productores deben producir café de calidad que será vendido con marca propia en mercados de cafés especiales, a un precio mayor que establece el mercado internacional... [De esta manera,] insto a los asociados de Libertad a 
sentirse orgullosos de esta cooperativa, a no bajar la guardia con el compromiso que cada uno tiene con la calidad, porque definitivamente lo estamos logrando." ${ }^{4}$

Ciertamente la crisis que había impactado al sector cafetalero, continuó azotando a los productores agrupados en CoopeLibertad, pues hacia el año 2001 se experimentaron nuevas bajas en los precios del café, provocadas en esencia por una sobreoferta del grano vietnamita, y por una serie de transformaciones en la cadena de comercialización mundial del grano. Muchos productores la describen como una de las peores crisis desde la baja en los precios de inicios de la década de 1990:

“es que la verdadera crisis fue la del dos mil para acá; dos mil tres, cuatro y cinco, esas tres cosechas fueron fatales, anterior no, ahí nos la jugábamos bien. Estas tres últimas cosechas, cuatro cosechas anteriores, esa fue la que apretó más por los malos precios... ahí fue donde nos apretó más la mala situación económica, muy mal la pasamos. Jueputis, no quisiera ni acordarme de eso. No había ni para comprar el diario de la casa, ni pa' la gasolina del carro, ni pa' pagar la luz. Bueno, algo terrible... $" 5$

A raíz de dicha tesitura, el productor continuó enfrentando épocas de precios fluctuantes, lo cual repercutió sobre los costos de producción y sobre la liquidación final de su producto. La cita evidenció la lenta recuperación que sufrió el caficultor ante la baja producción del grano, y como consecuencia, la baja retribución que adquirió por el mismo.

4 CoopeLibertad R.L "Con su apoyo lo estamos logrando". En: Al día con la Cooperativa, 01-2003, p 1. El texto entre llaves es propio y el resaltado aparece en el texto.

5 Entrevista inédita con Gerardo Chacón, caficultor asociado a la cooperativa. 9 de octubre del 2007, Santo Domingo, Heredia. 
Si bien el grupo siguió enfrentando dificultades financieras aún entrado el año 2000, las deudas y compromisos con otros organismos financieros no eran la única preocupación para la Junta Administrativa. El proceso de urbanización, el cual se acentuó desde el cantón Central hacia los distritos cafetaleros, a lo largo de la década de 1990, afectó el proceso productivo y de acopio del grano. ${ }^{6}$ Algunos caficultores heredianos describen el proceso como similar al que ocurrió en otras áreas cafetaleras del país fuertemente urbanizadas:

“... aquí [San Domingo de Heredia] hay un montón de fincas que están urbanizando. Ya dieron los permisos para sesenta casas. Ahí hay otras nueve manzanas que ahorita solo el cafecito que esta en las partes altas lo quitan para urbanizar. Allá en La Quintana [hay] otras fincas grandísimas ya para urbanizar, que están listas... ya el café en Santo Domingo ya no, va a pasar igual que Moravia...”7

$6 \quad$ Claudio Monge Garro. Efectos del proceso de urbanización sobre el recurso hidrográfico en la unidad geográfica del cantón de Barva. Heredia: Tesis de Licenciatura para optar al grado de Licenciado en Geografía, 1986, p 53 y siguientes.

7 Entrevista inédita con Gerardo Chacón, caficultor asociado a la cooperativa. 9 de octubre del 2007, Santo Domingo, Heredia. 


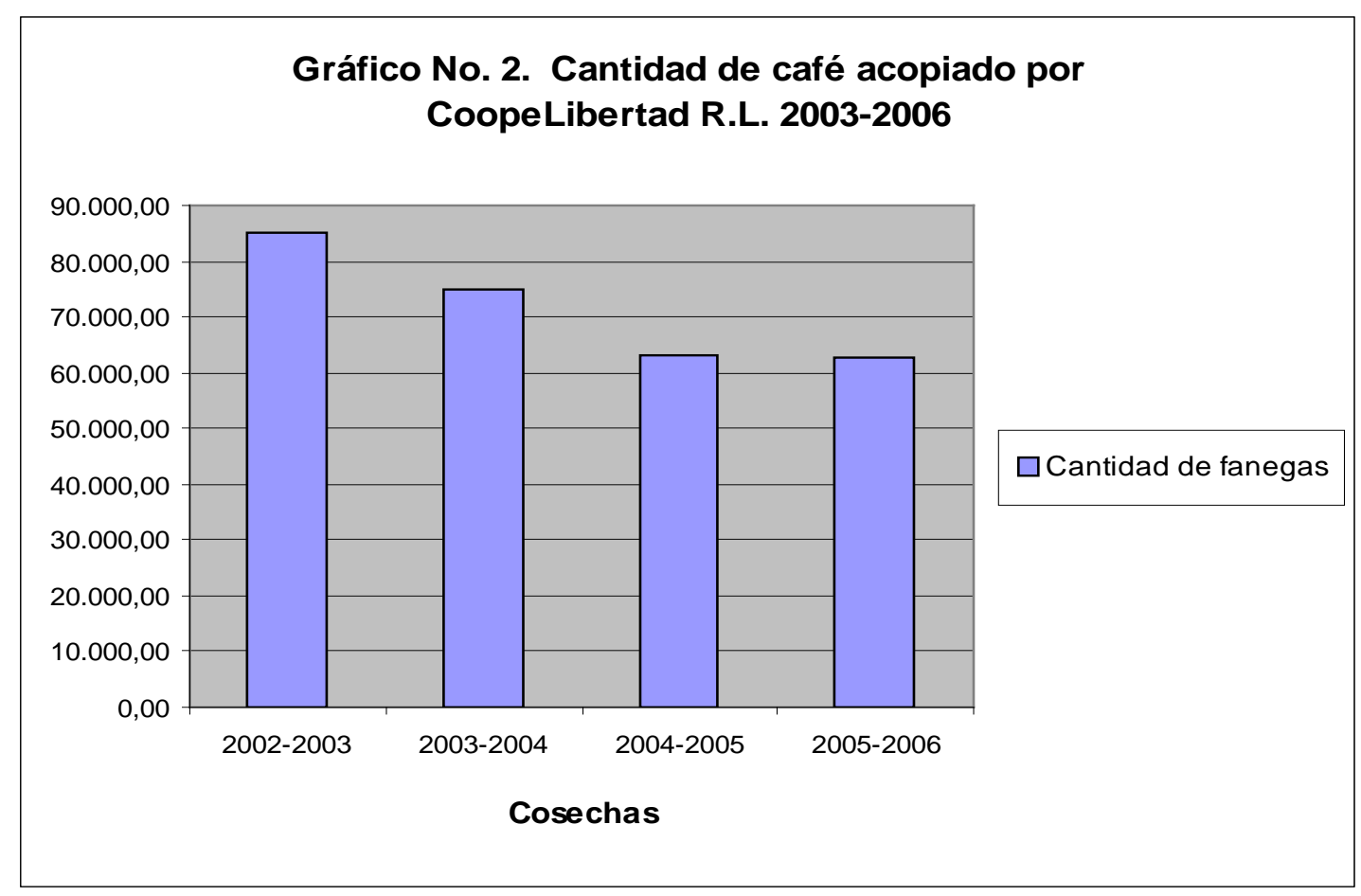

Fuente: Elaboración propia a partir de: Informes anuales de ventas y liquidaciones, CoopeLibertad R.L, 2000-

2006

Al mismo tiempo, este proceso repercutió sobre la generación ingresos para la cooperativa la cual percibe únicamente un 9 por ciento para sus gastos de operación (planillas, administración, instalaciones, operación del beneficio), mientras que el resto forma parte del pago al productor por concepto de liquidación. En el Gráfico No. 2 se puede observar un descenso en el recibo de café en el período 2003-2006, directamente asociado con proceso de urbanismo, y con la tendencia a la fragmentación de la propiedad cafetalera por repartición de herencias, retiro de los asociados por vejez o muerte y en respuesta, por parte de algunos, a las fuertes políticas de calidad como una exigencia de la cooperativa en la entrega de del grano.

Si en la década de los noventa se dio un cuadro de alta competencia entre CoopeLibertad y 
empresas beneficiadoras, como la ya extinta Corporación La Meseta, en el nuevo siglo aparecieron nuevas firmas beneficiadoras respaldadas por amplios capitales y recursos financieros como el grupo Volcafé, así como lo recuerda un caficultor herediano: "La cooperativa estuvo unos años, estuvo sola. Cerraron el beneficio Montealegre... y quedó prácticamente sola, pero ahora se les metió Volcafé"» A esto se suma el hecho de que otras tostadoras nacionales lograron incrementar el valor agregado de su café en la década de los noventa por medio de programas especiales de exportación, ${ }^{9}$ lo cual acrecentó la competencia entre firmas productoras del grano.

En este contexto, pareciera también importante considerar la influencia que tuvo el colapso de la Federación de Cooperativas de Caficultores (FEDECOOP) a nivel del movimiento cooperativo cafetalero. ${ }^{10}$ Ciertamente, el desplome de la Federación en la década de los noventa, constituyó una gran desventaja para las organizaciones frente a la consolidación de las grandes multinacionales como Volcafé, lo cual obligó a las cooperativas a buscar la forma de mantener al sector integrado y a buscar sus propias formas de comercializar el grano. ${ }^{11}$

Ante este difícil panorama, la Junta Administrativa de CoopeLibertad planteó la necesidad de reorganizar la estructura empresarial de una manera más agresiva con el fin de afrontar, no solo la competencia, sino el conjunto de adversidades implicadas por el rompimiento de los acuerdos y la liberalización del mercado. Sin embargo, la baja en los precios del año 2001, trazó

8 Entrevista inédita con Fernando Rodríguez, caficultor asociado a la cooperativa. 9 de octubre del 2007, Santo Domingo, Heredia.

9 "Costa Rica exporta café con alto valor agregado" La Prensa Libre, 18 de setiembre de 1996, p 13.

10 Hay que recordar que la Federación constituyó, por más de tres década el organismo estatal encargado del financiamiento, exportación y comercialización del café de las cooperativas. Con su caída, desapareció el último vestigio del apoyo estatal al movimiento cooperativo cafetalero.

11 Johnny Mora. La vía cooperativa de desarrollo del agro. El caso de Coopronaranjo R.L. Heredia: EUNA, 2007, P 217. 
el plan de implementar una estrategia que permitiera a la cooperativa competir frente al embate de las empresas transnacionales. Con este fin, CoopeLibertad volcó sus esfuerzos a producir un café de alta calidad que le permitiera posicionarse en nuevos nichos de mercado, principalmente norteamericanos, y así reducir la dependencia de los precios del mercado mundial. ${ }^{12}$

Esta iniciativa tuvo como consecuencia la aplicación de fuertes políticas orientadas a mejorar las características del café producido por los asociados de la cooperativa. El tema de la calidad, definida como "el conjunto de las características o atributos del producto, que busca adquirir un comprador, en momentos de una transacción mercantil" es una preocupación que surge, según Bertozzi, ${ }^{13}$ en contextos de saturación del mercado, como sucedió a partir del 2001 con el aumento en la oferta vietnamita.

Para adquirir una calidad óptima del producto, es necesario tomar en cuenta un conjunto de factores geográficos, climáticos y edafológicos como la altura, la humedad y la cantidad de nutrientes en el suelo, respectivamente. A esto se suma el mantenimiento constante de los cafetales a través de las labores estacionales y de la utilización del "paquete tecnológico" adaptados a tal objeto, con el fin de mantener los cafetos altamente productivos, lo cual representa la elevación en los costos de producción del caficultor y un mayor control de la cooperativa en el acopio del grano. De esta manera, en la Asamblea General Ordinaria de Delegados se aprobó no recibir café revuelto con sustancias que puedan alterar la calidad del grano, no recibir café cosechado del día anterior, llevar a cabo el muestreo de café para determinar flotes y no recibir

12 Esta estrategia pretende reducir la dependencia sobre los fluctuantes precios del mercado internacional y elevar el valor agregado del producto en nichos específicos, tales como la Starbucks Coffee o la Royal Coffee. Entrevista inédita con Carlos Villalobos, Gerente financiero de CoopeLibertad. Martes 18 de setiembre del 2007, Barva, Heredia.

13 Leo Bertozzi citado en Andrea Montero, José Aurelio Sandí y Carolina Zúñiga. Tarrazú y Orosi: estudio comparativo sobre calidad y fama del café en la cadena de comercialización, 1989-2005. (Inédito). Heredia: Maestría en Historia Aplicada UNA, 2006, p 7. 
café verde. ${ }^{14}$ Al mismo tiempo, la cooperativa adaptó su infraestructura física con el fin de mejorar procesamiento del grano.

En el Gráfico No. 3 se puede observar como en la cosecha 2001-2002 se elevaron los costos de operación de manera notable, a causa de las transformaciones en el beneficio húmedo, la modernización de los recibidores, el procesamiento de la broza y el tratamiento de aguas residuales. Esta serie de transformaciones evidenciaron la preocupación por proveer las condiciones necesarias para aumentar la calidad y no la cantidad del café producido por sus asociados.

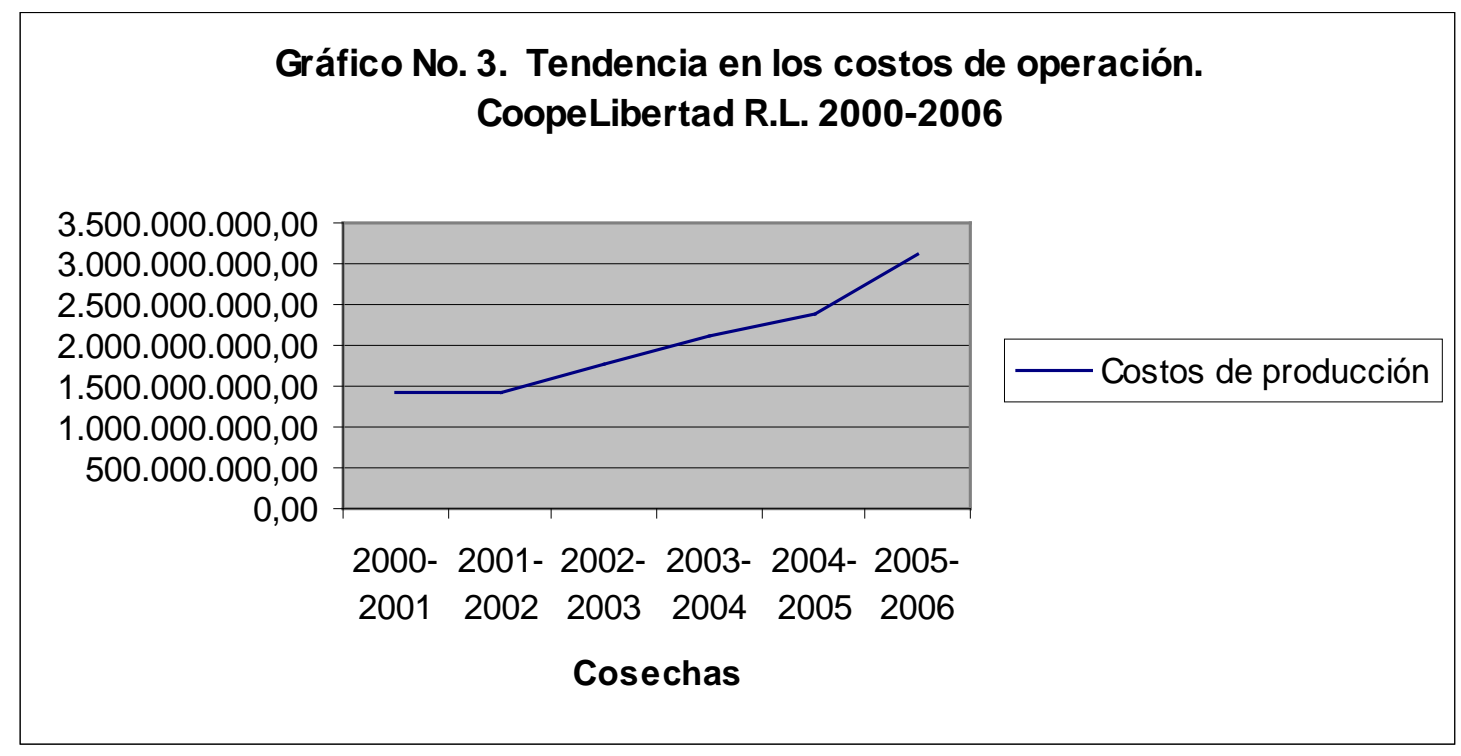

Fuente: Elaboración propia a partir de: Informes anuales de ventas y liquidaciones,

CoopeLibertad R.L, 2000-2006

14 No se permite entregar piedras, palos, hojas, chasparria, granos secos o brocados, ni café fermentado. Los máximos de café verde que se permiten son máximo 2por ciento antes de repela y 10 por ciento en repela. Véase CoopeLibertad R.L. "Políticas de calidad" En: Al día con la Cooperativa. 03-2004, p4. 
La importancia de producir café de alta calidad derivó de la necesidad de elevar los ingresos de la cooperativa por concepto de ventas. De esta manera se buscó comercializar el grano hacia mercados específicos, como empresas tostadoras, con el fin de eliminar los intermediarios ${ }^{15}$ que aparecieron tras el colapso de la FEDECOOP. La búsqueda de nuevos clientes en el exterior fue una estrategia vital para atraer compradores del café producido por la cooperativa y permitió consolidar relaciones comerciales con firmas europeas como UTZ KAPEH de Holanda. Los contratos fijados entre la cooperativa y estas compañías permitieron establecer precios para el grano superiores a los ofrecidos el mercado mundial, los cuales se encontraban por debajo de los costos de producción. ${ }^{16}$ Paralelamente, CoopeLibertad amplió sus políticas de mercadeo incursionando en la creación de marcas con diferentes características y atributos, esto con el fin de responder a las exigencias de diversos mercados. ${ }^{17}$

Estas transformaciones en buen grado permitieron a CoopeLibertad subsanar la crisis financiera arrastrada desde la década de 1990 y agudizada por la baja en los precios del 2001. Los resultados se reflejaron a través del constante crecimiento en el valor total de las ventas a lo largo del período. Se pudo apreciar un notable aumento en el valor de las ventas de exportación directa, las cuales prácticamente se duplicaron durante el período 2000-2006. Por otra parte, el valor de las ventas adquirido a través del consumo nacional no creció con la misma celeridad a lo largo del período, posiblemente como un mecanismo para reducir el costo en los impuestos a

15 Se trata de compañías comercializadoras locales encargadas del procesamiento y exportación del grano.

16 Entrevista inédita con Carlos Villalobos, Gerente financiero de CoopeLibertad. Martes 18 de setiembre del 2007, Barva, Heredia.

17 Ibidem. Por ejemplo, la marca Matinilla corresponde a un producto hecho a base de café producido a los 1200 metros sobre el nivel del mar y recolectado en pleno centro de cosecha, que es el período comprendido entre los últimos quince días del mes de noviembre y finales del mes de diciembre, y que corresponde a la época de mayor madurez del grano. 
Indexaciones: Repositorio de Revistas UCR, DIALNET, Latindex, REDALYC Directorio y recolector de recursos digitales del Ministerio de Cultura de España, Directory of Open Access Journals.

Diálogos Revista Electrónica de Historia ISSN 1409- 469X. Número especial 2008. Dirección web: http://historia.fcs.ucr.ac.cr/dialogos.htm

la comercialización del grano en mercados locales.

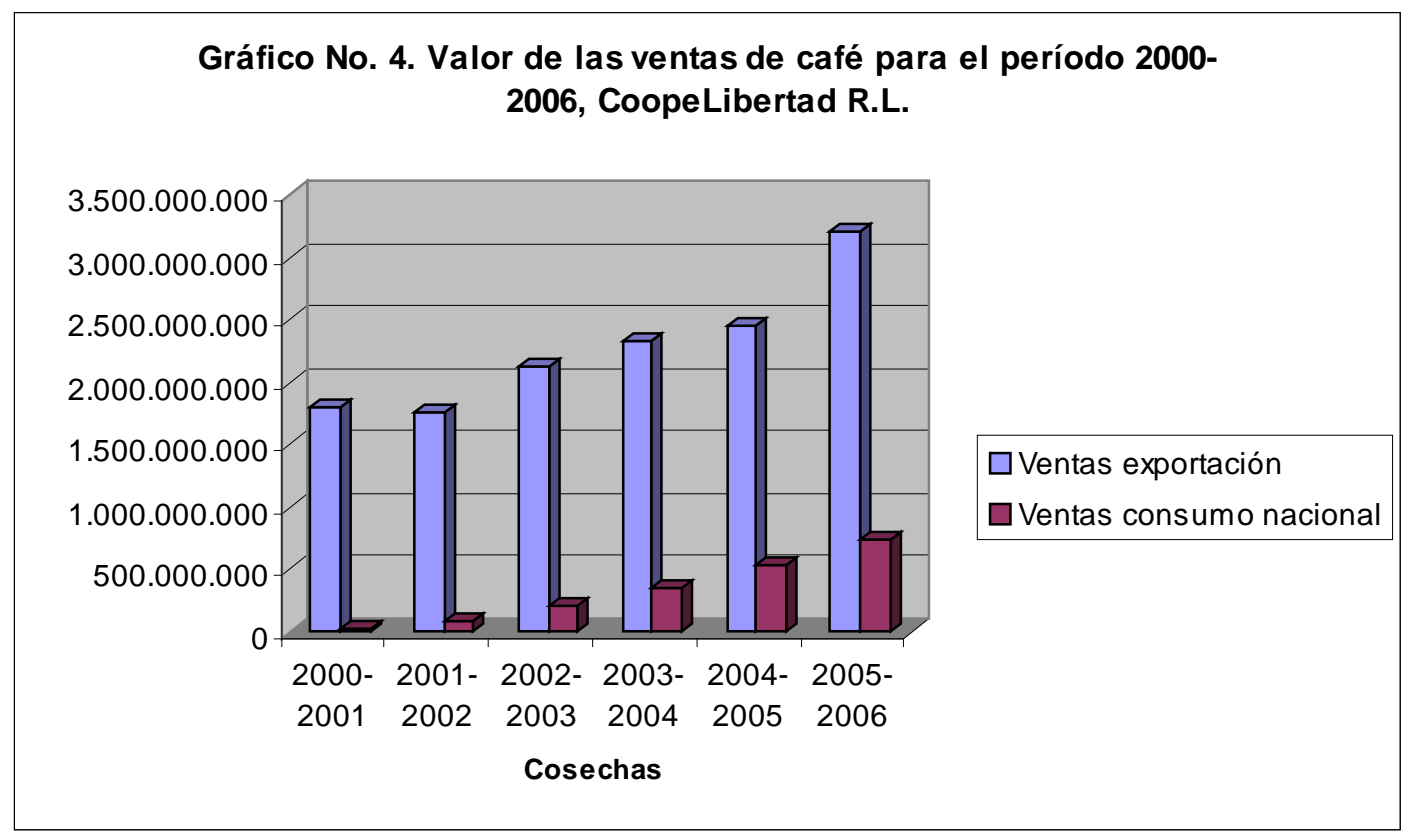

Este aumento en las ventas (Ver Gráfico No. 4) repercutió de manera positiva sobre la obtención de ingresos para la cooperativa, lo cual le permitió asumir el aumento de sus costos de producción y de operación, y restablecer servicios como el almacén de suministros y las líneas de crédito al productor. También permitió al grupo continuar con el pago de deudas a través de gestiones con otros organismos

Fuente: Elaboración propia a partir de: Informes anuales de ventas y liquidaciones, CoopeLibertad R.L, 2000-2006. 
como el Instituto de Fomento Cooperativo (INFOCOOP), con el cual logró obtener una refundición de deudas por un monto de seiscientos cincuenta millones de colones con una tasa de interés de 7 por ciento anual. ${ }^{18}$

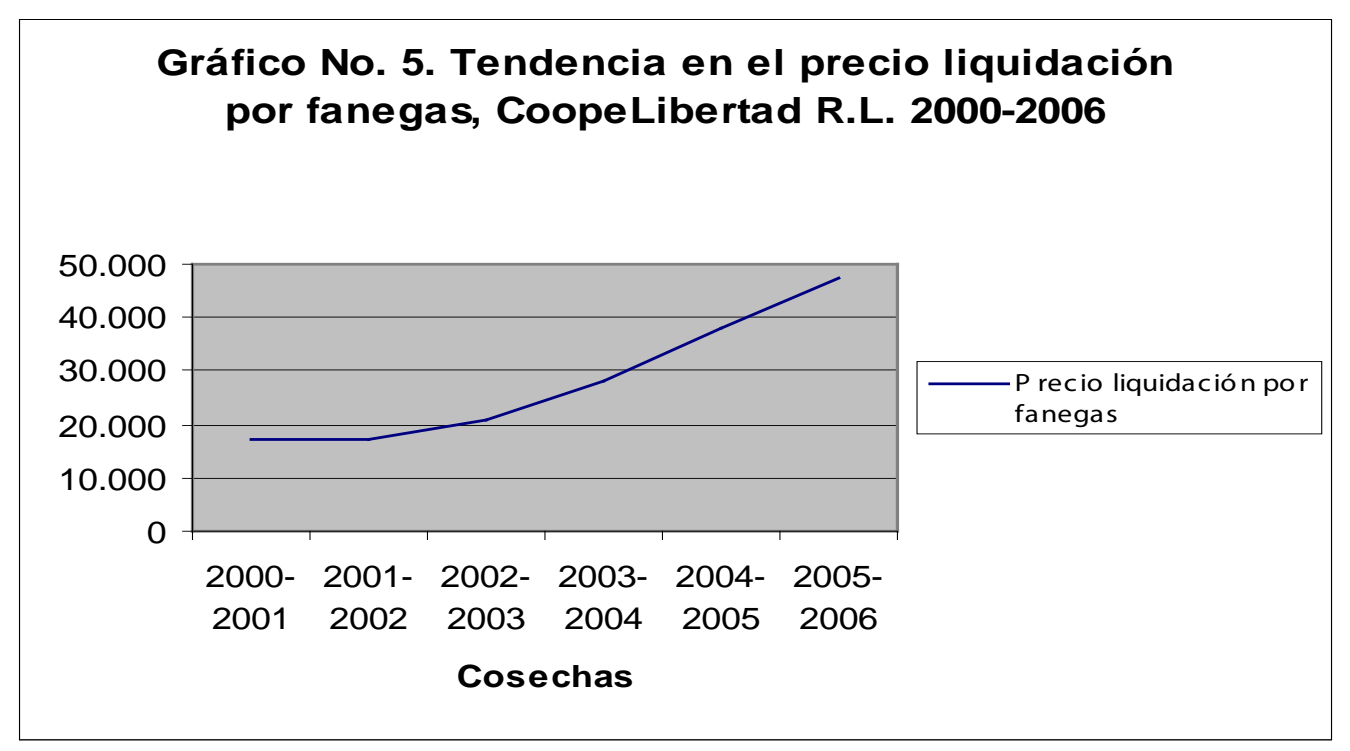

Fuente: Elaboración propia a partir de: Informes anuales de ventas y liquidaciones, CoopeLibertad R.L, 2000-2006

En lo referente al productor, el crecimiento de las ventas permitió aumentar los ingresos destinados al pago de la liquidación (Ver Gráfico No. 5 ), lo cual le permitió cubrir los gastos de producción (insumos, mano de obra) y el pago del Fondo de Estabilización Cafetalera, aprobado para el año 2002 por el gobierno. Adicionalmente, la Cooperativa implantó una serie de incentivos a la producción de café de calidad, con los cuales el productor aseguró tanto la cobertura de \begin{tabular}{lccccccc}
\hline 18 & CoopeLibertad & R.L. & Informes Consejo de & Administración y Ger- \\
encia. & Asamblea & General & de Delegados No78, & marzo del & 2004.
\end{tabular} 
los insumos como un ingreso extra. Así, por medio de las ferias agrícolas, el productor pudo adquirir fertilizantes y otros insumos al costo por determinada cantidad de fanegas entregadas y en el mes de octubre recibió el pago del premio a la calidad por la entrega de café únicamente maduro. Como se verá más adelante, esta serie de incentivos no solo beneficiaron al pequeño y mediano productor cafetalero aumentando sus ingresos por cantidad de fanegas, sino que además la cooperativa logró sacar partida de esta actividad.

Anteriormente, se logró establecer que el tema de la calidad permitió a CoopeLibertad solventar su situación financiera y mantenerse participando en el mercado cafetero, en medio de dos serias amenazas como lo fueron el proceso de urbanización y el "empuje de las transnacionales", ${ }^{19}$ al tiempo que le dio un respiro al pequeño productor cafetalero. No obstante, cabe preguntarse ¿cómo logró la cooperativa mantener las lealtades y reunir a sus asociados alrededor del proyecto de calidad? ¿cómo respondió el asociado a las nuevas transformaciones? Estas interrogantes se tratarán a continuación.

\section{Replanteando la cultura del caficultor: Reflexiones en torno al impacto de la crisis sobre las relaciones asociado-cooperativa.}

Los procesos de apertura y liberalización económica impactaron, sin lugar a duda, el proyecto estatal y la estructura económica costarricense. Las recientes crisis provocadas por la caída de los precios internacionales y la liberalización del mercado cafetero, aportaron las condiciones necesarias para el dinamismo de nuevos actores en la cadena de comercialización del grano. Al respecto, la consolidación de grandes empresas incorporadas a esta estructura, corrió paralelo al debilitamiento de la participación estatal en el negocio cafetero, lo que afectó

19 Johnny Mora. Op Cit, p 232. 
paulatinamente al sector cooperativo.

CoopeLibertad transformó tanto su estructura organizativa como empresarial con el fin de proteger los intereses de todos sus miembros, intereses tan diversos como las dificultades que enfrentó el grupo a lo largo de la década de los noventa. El proceso de urbanización herediano no fue simplemente una consecuencia más de la crisis, sino el fin de grandes áreas cafetaleras y de los intereses ligados a dicha actividad. Al fragmentarse la propiedad, desaparecieron los grandes "señores del café" de la región y al mando quedaron sus descendientes con nuevas propuestas, enmarcadas en una lógica capitalista más agresiva, con respecto a las políticas de comercialización llevadas a cabo por FEDECOOP; lo que a la sazón les permitió posicionarse en la cadena de comercialización del grano y mantenerse en el negocio cafetero, esta vez sacando ventaja de la fragmentada propiedad cafetalera y trasladando los costo de producción al pequeño caficultor. De esta manera, surgió el componente de la calidad como tabla de salvación, no solo del asociado sino de los altos mandos de la corporación.

En este contexto, la cooperativa llevó a cabo una campaña de conscientización acerca de la importancia de adquirir un mejor producto, en consonancia con las tendencias de un mercado que ya no exigía cantidad sino calidad, e implantó políticas para mejorar las características del grano. Esto tuvo como consecuencia que el productor caficultor replanteara toda su cultura de producción del grano, existente desde la misma aparición del cultivo en Costa Rica; lo cual como ha quedado demostrado, se reflejó en la disminución de los volúmenes de café acopiado por la cooperativa. En muchos productores predominaba la costumbre de coger café verde, seco o recogido del suelo, enfatizando la cantidad sobre la cantidad. CoopeLibertad y otras cooperativas habían puesto en manos de FEDECOOP las tareas de procesamiento, comercialización y exportación del grano hasta el momento en que la Federación cesó sus funciones, razón por 
la cual la preocupación por la calidad no estuvo tan marcada durante la década de 1990. No obstante, esto cambió a partir del establecimiento de los llamados "medidores", ${ }^{20}$ instalados en los recibidores de café bajo la consigna de recibir café preferentemente maduro.

Si bien este hecho no confrontó al productor asociado con los altos mandos, sí lo hizo con los encargados del recibo, quienes se ocupaban de "castigar" el café defectuoso. Estos conflictos afectaron de manera directa la relación entre el asociado y su cooperativa, al punto de provocar el distanciamiento de algunos miembros. Tomás Arce, productor de café, externó su punto de vista al respecto:

“...mirá, antes a uno le decían ‘junte el café seco’, ahora Dios libre usted le eche café seco... y que culpa tiene uno que el café se le seque... y si le digo a los peones que me cojan solo el grano totalmente cien por ciento maduro, diay, hay que pagarles seguramente cinco mil pesos la cajuela. Y ese señor (el medidor) me hizo algunas advertencias, como amenazantes... Le digo: usted sabe que si traigo diez cajuelillas de granea y usted me castiga tres, diay mejor las boto... y sabe que? Usted va a perder también; porque si yo dejo de ser cooperativista y el otro deja de ser cooperativista y no lo atienden y no lo escuchan, hay menos cooperativistas, entonces no tiene sentido la cooperativa... todo se cierra"21

No obstante, otros productores están de acuerdo con que si bien CoopeLibertad exigía determinadas características de calidad, por otra parte compensaba por medio de una serie de 20 Los medidores son empleados que laboran en los recibidores de las cooperativa y que operan realizando una serie de pruebas al grano para comprobar la calidad del grano. Estas pruebas determinan la cantidad granos fermentados, brocados, secos y con otros defectos que puedan dañar la la capacidad de café a beneficiar.

21 Entrevista inédita con Tomás Arce, caficultor asociado a la cooperativa. Lunes $1^{\circ}$ de octubre del 2007, Santo Domingo, Heredia. 
incentivos a la calidad, los cuales pagaba como parte de la liquidación final. Asociados como Vera Gonzáles enfatizan la importancia de producir café de calidad y de transformar las prácticas de recolección del grano:

“...a la par de que le castigan por el [café] verde, también le premian la calidad; si uno lo lleva en las condiciones que ellos lo piden, entonces monetariamente le van a premiar... y ahora, eso también lo obliga a uno a darle buen mantenimiento al cafetal, para eliminar la broca por ejemplo... "22

Por otro lado, la aparición de poderosas empresas transnacionales como Volcafé puso a prueba la lealtad del asociado hacia CoopeLibertad, y de hecho hacia otras cooperativas. ${ }^{23}$ Como antes se ha visto, estas empresas contaban con recursos financieros suficientes para entregar altos adelantos de cosecha a los productores, lo cual constituyó una gran "tentación" para el productor, quien recibió por parte de la cooperativa los adelantos en varios pagos a lo largo del año y quien necesitaba cubrir los costos de producción, pagar sus deudas y alimentar a su familia. Esta realidad se hizo más evidente a partir de la década de los noventa, cuando el Estado dejó de financiar, por completo, la actividad cafetalera.

Ciertamente, estos "lobos con piel de oveja" atrajeron muchos productores a entregar todo tipo de café: verde, maduro, seco, chasparria, etc. Esto redujo la cantidad acopiada por la cooperativa y puso en aprietos a la Junta Administrativa, la cual tuvo que buscar los recursos para cubrir los gastos de mantenimiento de un beneficio que no lograba alcanzar su máximo.

22 Entrevista inédita con Vera González y Roldán Briceño, caficultores asociados a la cooperativa. $1^{\circ}$ de octubre del 2007, Santo Domingo, Heredia.

23 El caso de Coopronaranjo es interesante, pues presentó las mismas dificultades que CoopeLibertad ha venido arrastrando ante la consolidación de estas empresas en nuestros país. Vease Johnny Mora. Op Cit. 
Ante esta situación, la empresa se vio obligada a ser más flexible en sus políticas de calidad, aceptando un máximo de café verde y discriminando aquél grano que pudiera contaminar el café en buen estado. Al mismo tiempo, se implantó una política de incentivos a la calidad con el fin de atraer viejos asociados y a productores independientes que no gozan, en igualdad de condiciones, de los beneficios que poseen los asociados (crédito, suministros, asesoría técnica). Por otra parte, las alianzas con compañías cafeteras internacionales, como Rain Forest Alliance, Green Mountain o Utz Kapeh; permitieron a CoopeLibertad impulsar políticas de producción de café certificado como un aliciente a la producción de calidad en armonía con el ambiente y bajo parámetros de resguardo social hacia los trabajadores. ${ }^{24}$

Muchas de las decisiones tomadas por CoopeLibertad, a lo largo de este período, le permitieron mantenerse como una institución sólida a pesar de las recurrentes crisis que vivieron sus productores. No obstante, otras medidas redujeron la participación y la cohesión del grupo cooperativo, ${ }^{25}$ al punto de colocarlos tanto a los pies de las transnacionales, como a merced del progreso y la modernización acrecentando el proceso de urbanización en la zona. Muchos productores comprendieron que el café perdía su rentabilidad año a año y perdieron la esperanza de recuperarse:

“...yo considero que el café no es un producto rentable. Entonces desde el principio yo no estoy muy convencido en el mismo café. En otra época era importante, tal vez con la bonanza... pero yo estaba pequeñillo en ese momento” ${ }_{26}$

24 Entrevista inédita con Oscar Luis Salazar, empleado de la cooperativa. Barva de Heredia, 29 de agosto del 2007.

25 CoopeLibertad R.L. Informe citado. Asamblea general Ordinaria de Delegados $\mathrm{N}^{\circ} 61$, julio de 1988.

26 Entrevista inédita con Tomás Arce, caficultor asociado a la cooperativa. Lunes $1^{\circ}$ de octubre del 2007, Santo Domingo, Heredia. 
Gracias a la amplia trayectoria de CoopeLibertad, muchos productores continúan en el negocio cafetero y han logrado salir adelante a través de la proyección social que mantiene la cooperativa con la población. Hoy día, el grupo se ha consolidado como una de las más importantes productoras de café de calidad del país gracias a una inteligente gestión empresarial.

\footnotetext{
"Es otra administración completamente distinta... ahora uno ve orden, la atención ahí al asociado es otra cosa, solicita uno un crédito ahí para suministros se lo dan inmediatamente... la atención técnica es muy buena. El asociado entendió que la única manera de [obtener] buenos precios es entregando buen café... todo cambió”27
}

Mientras muchos productores se pasaron a la competencia, otros permanecieron ligados a la cooperativa como parte de una tradición familiar de entregar café a la "Coope". Muchos vieron crecer a sus hijos alrededor de este grupo, y estos tomaron el relevo de sus padres con el paso de los años. Otros lograron sobrevivir, pero pocos tuvieron el espíritu y decisión para continuar adelante frente a los estragos provocados por las crisis.

27 Entrevista inédita con Gerardo Chacón, caficultor asociado a la cooperativa. 9 de octubre del 2007, Santo Domingo, Heredia. 


\section{Consideraciones finales}

Este trabajo intentó resolver el impacto de la caída en los precios internacionales del café y la liberalización del mercado cafetero sobre las líneas empresariales del grupo CoopeLibertad. Efectivamente, la crisis de los precios internacionales influyó sobre la obtención de ingresos de la cooperativa. Las bajas cotizaciones impidieron que el caficultor asociado obtuviera los recursos necesarios para el mantenimiento de los cafetales, lo cual repercutió en una baja productividad y en bajos niveles de acopio del grano. Como consecuencia, el grupo sufrió una severa descapitalización a raíz de la reducción en las utilidades generadas por concepto de ventas del grano en el exterior, lo cual también afectó, evidentemente, los precios de liquidación al productor y las posibilidades de obtener créditos y otros servicios por parte de la cooperativa. Esto fue un ciclo que se repitió a lo largo de la década de los noventa a causa de las fluctuantes condiciones del mercado cafetero internacional.

Por otra parte, la estrategia de liberalización del mercado cafetero internacional llevada a cabo por los países importadores del grano (principalmente Estados Unidos) jugó un papel importante en el proceso de consolidación de grandes empresas transnacionales, con amplios recursos financieros e integrados verticalmente en la cadena de producción y comercialización del grano, lo cual les permitió competir en un mercado libre con las empresas cooperativas costarricenses, entre ellas CoopeLibertad. Sumado a esto, con el debilitamiento del entorno institucional a partir de la implementación de los Programas de Ajuste Estructural y la liberalización de la economía, la cooperativa se vio envuelta en una encrucijada: ampararse en un débil Estado, el cual dio la espalda a una actividad que dinamizó la economía por más de siglo y medio; o buscar mecanismos eficientes para contrarrestar las constantes bajas en los precios. 
El mejoramiento de la calidad del grano constituyó la mejor opción adoptada por la cooperativa para enfrentar los efectos de la crisis de inicio de siglo y se convirtió en un mecanismo inteligente para acceder a nuevos nichos de mercado, por medio de alianzas estratégicas con organismos cafeteros internacionales, y de esta manera, consolidar su posición en el negocio cafetero. Dicha estrategia consistió en la aplicación de un conjunto de políticas dirigidas a obtener un grano cien por ciento maduro y de alta calidad, con el fin de atender a las exigencias de los compradores.

De manera complementaria, la investigación intentó resolver las transformaciones producidas en las relaciones entre la cooperativa y sus miembros. Conviene plantear, que con el ascenso de grupos socialdemócratas al poder, el Estado resolvió la relación entre beneficiadores privados y pequeños o medianos productores, y fomentó la actividad cafetalera proporcionando insumos y crédito. Con los Programas de Ajuste Estructural, el Estado eliminó todo tipo de subsidio a la actividad cafetalera (a excepción del FONECAFE) y se preocupó por recuperar recursos a través de nuevos impuestos a la actividad. Esto, sumado a la liberalización de mercado cafetero, terminó de consolidar la aparición de firmas transnacionales altamente competitivas, lo cual transformó los criterios de eficiencia y competitividad de la cooperativa, en un contexto en el cual la calidad es más importante que el volumen. Esto obligó al grupo a trasladar los costos de producción al caficultor (anteriormente financiados por el Estado a través del sistema bancario nacional), quien con sus ingresos debió asegurar la producción de un grano de alta calidad.

El presente producto, al encontrarse enmarcado en un largo proceso de aprendizaje, estuvo propenso a la aparición de diversas dificultades, y como consecuencia de ello, a falencias que repercutieron en el proceso de investigación. Cabe destacar que, a pesar de los esfuerzos del grupo cooperativo por proporcionar información valiosa, no fue posible obtener fuentes de 
información referentes al desempeño de la empresa para la década de 1990, ya que mucha de la documentación que fue transferida a diferentes organismos públicos y privados, se encontró muy dispersa. La falta de recursos y la poca disponibilidad de tiempo para rastrear dichas fuentes, repercutieron sobre los resultados aquí expuestos, no obstante, no fueron despreciables los esfuerzos de la cooperativa por apoyar la investigación, ni las conclusiones a las que se llegaron.

Del mismo modo, el trabajo se limitó a puntualizar dos aspectos que podrían ser desarrollados posteriormente, por el autor o por otros investigadores, y que afectaron el desempeño de la cooperativa hasta nuestros días. El primero se refirió a la influencia de la fuerte presión urbana en la provincia de Heredia sobre las redes de acopio del grano. Este proceso se podría fundamentar más a fondo a través de mapas de uso de suelo, hojas cartográficas e información disponible en las municipalidades de los principales distritos cafetaleros. El segundo se refirió al impacto de las empresas transnacionales sobre la red de productores de la cooperativa, quienes en momentos de crisis consideraron dichas firmas como una posible opción para enfrentar los efectos de las bajas en las cotizaciones. Este tópico podría ser abordado a través de los testimonios de caficultores que decidieron entregar su café a firmas como "La Meseta", o recientemente, a Volcafé, la cual también opera, hoy día, en la zona de Heredia.

Esta investigación se volcó a explicar la importancia de la calidad como la estrategia más importante para afrontar las constantes bajas en los precios internacionales. Sin embargo, no se incluyeron otras opciones que pudieron ser consideradas por la cooperativa para reducir el impacto de la crisis. Posteriormente, se podrían analizar las diversas respuestas empresariales que formuló la cooperativa durante la década de los noventa para enfrentar tanto las fluctuaciones del mercado como el embate de las empresas transnacionales. Incluso, sería interesante realizar 
estudios comparativos sobre las respuestas de otras empresas cooperativas a la crisis del sector.

A pesar de las faltas anteriormente citadas, se puede considerar que el proceso de investigación generó, al menos, propuestas novedosas para el abordaje de la temática del café para los últimos quince años. Algunos de los trabajos consultados en el desarrollo de este producto, se ocupan de la crisis desde la perspectiva de las condiciones del mercado internacional, no obstante, el análisis de las respuestas ofrecidas por el Estado frente a la caída de los precios no ha sido suficientemente abordado. Al respecto, la investigación ofreció una breve incursión en el tratamiento de la fuente periodística para explicar las relaciones entre el Estado y el sector cafetalero en el contexto de debilitamiento de las estructuras estatales.

Otra de las fortalezas de la investigación es el trabajo con fuentes orales el cual, si bien no proporcionó importantes testimonios para la coyuntura crítica de la cooperativa en el decenio de los noventa, permitió dar una interpretación acerca del desarrollo de las relaciones entre la cooperativa y sus asociados en el período más reciente. Por otro lado, las entrevistas confirmaron la importancia que tuvieron el proceso de urbanización y el fortalecimiento de las transnacionales en el desempeño de la cooperativa y de los productores.

Como seha adelantado, la investigación, al formar parte de un proceso de retro alimentación, generó otras preguntas y perspectivas de análisis a futuro. En relación a las respuestas ofrecidas por el Estado para enfrentar la crisis del sector cafetalero, sería interesante conocer cuál ha sido la efectividad del FONECAFE como apoyo al pequeño y mediano caficultor, así como los parámetros utilizados en la distribución de dicho fondo (producción por fanega, ingresos, tamaño de finca, entre otros). Además, con el debilitamiento de las instituciones estatales y su apoyo a la actividad, ¿cuáles efectos tuvo la desestructuración de FEDECOOP sobre el sector cafetalero?; por otro lado, ¿cómo respondieron las cooperativas a tales efectos? Esta serie de 


\section{OI 9० CONGRESO \\ - $:$ CENTROAMERICANO \\ DE HISTORIA \\ Universidad de costa Risa}

Indexaciones: Repositorio de Revistas UCR, DIALNET, Latindex, REDALYC Directorio y recolector de recursos digitales del Ministerio de Cultura de España, Directory of Open Access Journals. Diálogos Revista Electrónica de Historia ISSN 1409-469X. Número especial 2008. Dirección web: http://historia.fcs.ucr.ac.cr/dialogos.htm

preguntas comprueban que, la problemática del café en Costa Rica aún no se ha agotado y que, posteriormente, será posible desarrollar nuevas propuestas, explicaciones e interpretaciones acerca del tema. 


\section{Fuentes consultadas}

\section{Fuentes primarias}

\section{Documentos de CoopeLibertad}

CoopeLibertad R.L. Informe de la Junta Administrativa. Asamblea General Ordinaria $\mathrm{N}^{\mathrm{o}} 24,14$ de junio de 1970.

CoopeLibertad R.L. Informe de Gerencia. Asamblea General Ordinaria $N^{0}$ 27, 23 de enero de 1972.

CoopeLibertad R.L. Informe de la Junta Administrativa. Asamblea General Ordinaria No 28, 11 de junio de 1972.

CoopeLibertad R.L. Informe de gerencia. Asamblea General de Delegados № 59, julio de 1987.

> CoopeLibertad R.L. Informes de Gerencia y Administración. Asamblea General Ordinaria de Delegados $\mathrm{N}^{\circ} 61$, julio de 1988.

CoopeLibertad R.L. Informe de Gerencia. Asamblea General Ordinaria No 63, abril de 1990.

$>$ CoopeLibertad R.L. Informe de Gerencia. Asamblea General de Delegados $N^{\circ}$ 67, 
septiembre de 1993.

CoopeLibertad R.L. Informe del Comité Administrativo. Asamblea General de Delegados No 68, abril de 1994.

CoopeLibertad R.L. Grano tras grano cosechando para el futuro. Memoria $35^{\circ}$ Aniversario. Heredia, 1996.

CoopeLibertad R.L. Informes de Gerencia y Administración. Asamblea General Ordinaria de Delegados № 77, abril del 2003.

CoopeLibertad R.L. Informes de Administración y Gerencia. Asamblea General de Delegados $\mathrm{N}^{\circ}$ 78, marzo del 2004.

CoopeLibertad R.L. Informes de Administración y Gerencia. Asamblea General de Delegados Nº 79, abril de 2005.

> CoopeLibertad R.1. Informes anuales de ventas y liquidaciones, 2000-2006.

CoopeLibertad R.L. "Con su apoyo lo estamos logrando". En: Boletín Al día con la Cooperativa. Heredia, 01-2003. 


\section{Entrevistas}

Entrevista $n^{\circ} 1$ con Salazar, Oscar Luis (empleado de la cooperativa). Inédita. Barva de Heredia, 28 de mayo del 2007.

Entrevista $\mathrm{n}^{\circ} 2$ con Salazar, Oscar Luis (empleado de la cooperativa). Inédita. Barva de Heredia, 29 de agosto del 2007.

Entrevista con Campos, Gerardo (empleado de la cooperativa). Inédita. Barva de Heredia, 29 de agosto del 2007.

Entrevista con Villalobos, Carlos (Gerente Administrativo CoopeLibertad R.L). Inédita. Barva de Heredia. Martes 18 de setiembre del 2007.

Entrevista con Arce, Tomás (productor asociado). Inédita. Santo Domingo de Heredia $1^{\circ}$ de octubre del 2007.

Entrevista con Barquero, Célimo (productor asociado). Inédita. Santo Domingo de Heredia. 11 de octubre del 2007.

Entrevista con Chacón, Gerardo (productor asociado). Inédita. Santo Domingo de 
Heredia. 9 de octubre del 2007.

Entrevista conjunta con González, Vera y Briceño, Roldán (ambos, productores asociados). Inédita. Santo Domingo de Heredia. $1^{\circ}$ de octubre del 2007.

$>$ Entrevista con Rodríguez, Fernando (productor asociado). Inédita. Santo Domingo de Heredia. 9 de octubre del 2007.

\section{Fuentes secundarias}

Acuña, Víctor Hugo “La ideología de los pequeños y medianos productores cafetaleros (1900-1961).” En: Revista de Historia. N ${ }^{\circ}$ 16, Heredia, Universidad Nacional, juliodiciembre (1987).

Araya P, Carlos. "Liberación Nacional en la historia política de Costa Rica 1940-1980". San José, Editorial Nacional de Textos, 1982.

Cazanga, José. "Las cooperativas de caficultores en Costa Rica". San José, Alma Máter, 1987.

Durán, Norman. "Evolución de los sistemas productivos y relaciones de poder entre los agentes sociales que conforman la cadena productiva de la caña de azúcar el distrito de El General, Pérez Zeledón 1950-2000”. Tesis de Maestría en Historia Aplicada, Universidad Nacional, 2005. 
Instituto del Café de Costa Rica. "Informe sobre la actividad cafetalera en Costa Rica 1994.” San José, 1995.

> “Informe sobre la actividad cafetalera en Costa Rica 1997." San José, 1997.

Jiménez Castro, Álvaro. “Costa Rica y el nuevo Convenio Internacional del Café.” San José, Cámara Nacional de Exportadores, 1993.

Monge Garro, Claudio. "Efectos del proceso de urbanización sobre el recurso hidrográfico en la unidad geográfica del cantón de Barva." Heredia, Tesis de Licenciatura para optar al grado de Licenciado en Geografía, 1986.

Montero, Andrea; Sandí, José Aurelio y Zúñiga, Carolina. “Tarrazú y Orosi: estudio comparativo sobre calidad y fama del café en la cadena de comercialización, 19892005”. (Inédito). Heredia, Maestría en Historia Aplicada UNA, 2006.

Mora, Johnny. "La vía cooperativa de desarrollo del agro. El caso de Coopronaranjo R.L.” Heredia, EUNA, 2007.

Pelupessy, Wim. “El mercado mundial del café”. San José, DEI, 1993.

Reubén, William. "Ideología y poder en el seno de las cooperativas de caficultores de 
Costa Rica”. En: Revista de Ciencias Sociales. San José, No 1 especial, julio-1984, Universidad de Costa Rica.

D Rojas, Edgar. "Efectos de la actual crisis cafetalera en la economía de Costa Rica". Heredia, Departamento de Estudios Agrícolas y Económicos del ICAFE, 1993.

Samper, Mario (Comp). "Crisis y perspectivas del café latinoamericano" San José, ICAFE-UNA, 1994.

Villasuso, Juan Manuel (comp). "El nuevo rostro de Costa Rica". Heredia, CEDAL, 1992.

Víquez, Gerardo y López, Leonidas. "Informe de Costa Rica". Heredia, Centro de Estudios Democráticos de América Latina, 1971. 